\title{
Effect of Cathode thickness on the performance of the cell $\mathrm{Li}$ / PAN:EC:PC:LiCF $\mathrm{SO}_{3} / \mathrm{PPy}:$ DBS
}

\author{
K. P. Vidanapathirana ${ }^{1 *}$ and M. A. Careem ${ }^{2}$ \\ Department of Electronics, Wayamba University of Sri Lanka, Kuliyapitiya ${ }^{1}$, \\ Department of Physics, University of Peradeniya, Peradeniya ${ }^{2}$.
}

\begin{abstract}
Electronically conducting Polypyrrole $\left(\mathrm{PPy}-\left[\mathrm{C}_{4} \mathrm{H}_{5} \mathrm{~N}\right]_{x}\right)$ has been identified as a good candidate for cathode material in Li rechargeable cells. Most of early studies have used smaller inorganic anions as doping species. However the performances of these cells were not promising due to poor stability of polymer film and lower capacity of the cell. It has been found out that use of large surfactant anions provide much stable films with better capacity. In this study, PPy films were synthesised using a large surfactant anion and the effect of the film thickness on the performance of the cells were investigated using cyclic voltammetry. It has been found that maximum performance could be obtained with thinner PPy cathodes.
\end{abstract}

\section{INTRODUCTION}

The use of conducting polymers as electrolyte or electrode material for the development of plasticlike electrochemical devise is an appealing concept. It is known that electronically conducting polymers, such as poly(acetylene), polypyrrole (PPy) or polyaniline commonly called polymer electrodes could be cycled in lithium batteries as well as the common inorganic oxide intercalation cathodes.

Out of all, PPy has been widely studied as a candidate for cathode material for Li rechargeable cells [1]. However most studies have been carried out using inorganic anions as the doping species and it has also been reported that cycling capacity of those cathodes is very low and their stability is very poor [2]. It has been reported that use of large surfactant anion salts provides a solution for above drawbacks [2]. In this study a large surfactant anion salt, Sodium dodecyl benzene sulphonate (SDBS), was used as the doping anion and the effect of the thickness of the PPy cathode on the cell performance is reported.

*Corresponding author, e-mail: kamalpv@sltnet.lk 


\section{EXPERIMENTAL}

\subsection{Film preparation}

PPy / DBS films for electrodes were prepared on a polished stainless steel disk. Film was deposited galvanostatically in a three electrode cell. The polymerization electrolyte was an aqueous solution of 0.05 M SDBS and 0.2 M pyrrole monomer. Current density used was $1 \mathrm{~mA} \mathrm{~cm}^{-2}$. Standard Calomel Electrode (SCE) and a Pt wire were used as reference and counter electrodes. Three different films were prepared with the estimated thicknesses of 1, 2, $4 \mathrm{~mm}$. After polymerization, films were thoroughly rinsed with distilled water.

\subsection{Electrolyte preparation}

A polymer electrolyte based on polyacrylonitrile (PAN, ALDRICH) was used. It was prepared using the method given by K. M. Abraham et al [3].

\subsection{Cell fabrication}

A special brass sample holder was used for this purpose. Complete procedure was carried out in an Ar filled glove box. A circular shape membrane was cut from the electrolyte to the size of the PPy / DBS film and used as a separator. A piece of Li metal of the same diameter was used as the anode. The battery was assembled in the configuration of PPy : DBS / PAN : EC : PC : $\mathrm{LiCF}_{3} \mathrm{SO}_{3} / \mathrm{Li}$.

\subsection{Cyclic Voltammetry}

First the open circuit voltage of the cell was measured. Then the cell was reduced to 2.2 V starting from the open circuit voltage. Thereafter several cyclings were performed in the potential range 2.2 to $3.5 \mathrm{~V}$ with respect to Li with different sweep rates. Here PPy served as working electrode while Li acted as both counter and reference electrodes.

\section{RESULTS AND DISCUSSION}

Cyclic voltammetry studies were done for the cells made with different thicknesses of PPy / DBS films at various scan rates. Cyclic voltammograms obtained for the cell with PPy / DBS $1 \mathrm{~mm}$ film is given in Fig. 1. This graph shows electrochemical behaviour of the films when the voltage changes form the $2.2 \mathrm{~V}$ to $3.5 \mathrm{~V}$ versus Li reference electrode. The positive half of the curve represents oxidation of the PPy film while the negative half represents the reduction.

Fig. 1(a) shows the cyclic voltammograms at lower sweep rates ( 0.1 to $2 \mathrm{mV} \mathrm{s}^{-1}$ ). When the cycling speed is increased, the peak positions seem to be shifting apart resulting much broader peaks with less capacity. This is obvious since the oxidation and reduction process could not follow the high sweep rate. In other words, the total reaction that should occur at a particular potential will not take 
place and will be shifted to higher potentials. So the peak is getting broader and the peak position is shifted towards higher potentials. These features are also visible in Fig. 1(b), in which the cycling capacity has drastically dropped when the scan rate is increased from $5 \mathrm{mV} \mathrm{s}^{-1}$ to $100 \mathrm{mV} \mathrm{s}^{-1}$. But when the scan rate is very low (eg. $0.1 \mathrm{mV} \mathrm{s}^{-1}$ ), the peak separation becomes less indicating complete electrochemical reversibility [4]. Performance variation with thicknesses (1, 2 and $4 \mathrm{~mm}$ films) at the sweep rate of $0.2 \mathrm{mV} \mathrm{s}^{-1}$ is given in Fig. 2 .
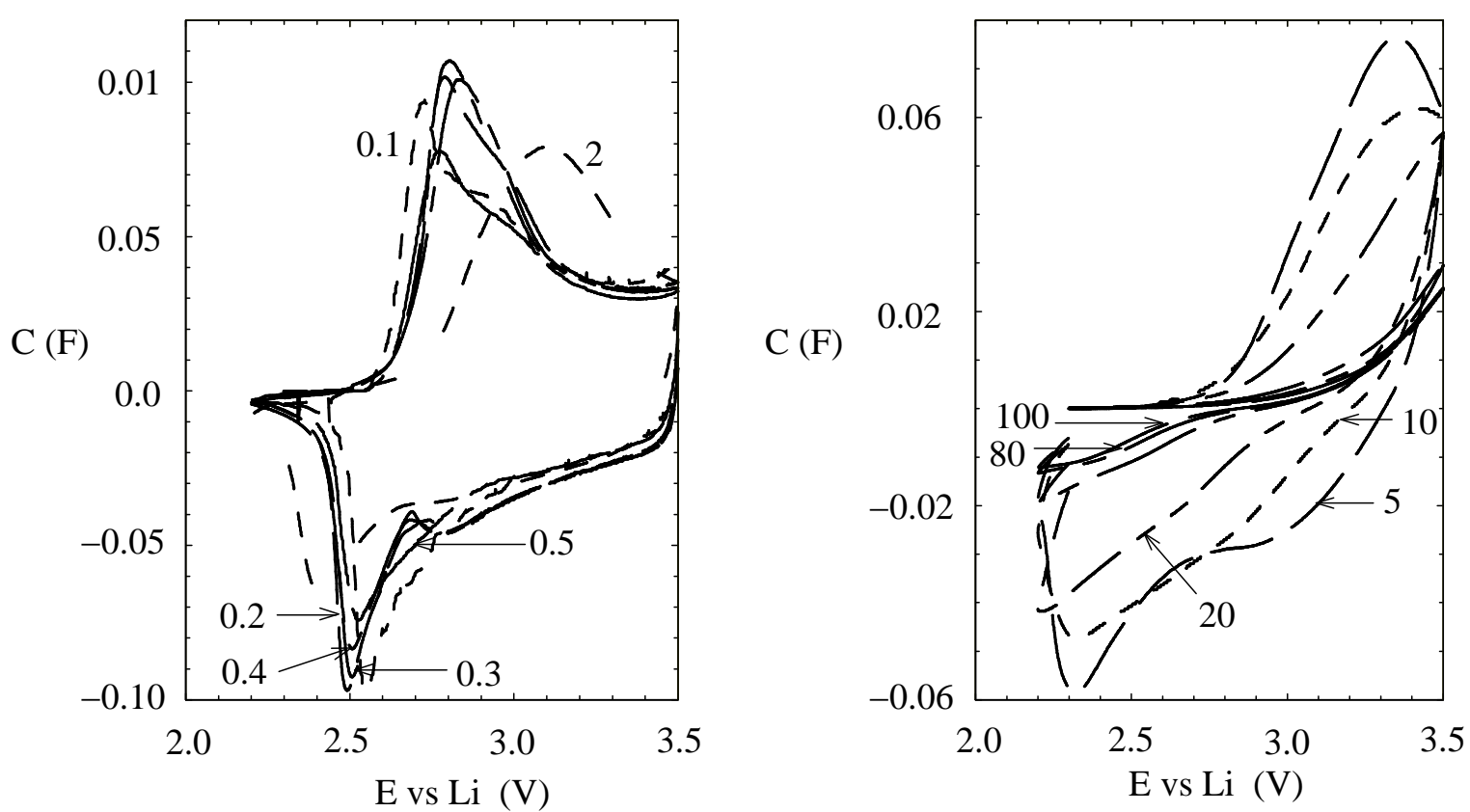

Fig. 1 Cyclic voltammogram of a cell at different scan rates, PPy film thickness is $1 \mathrm{~mm}$. (a) cyclic voltammograms with scan rates 0.1 to $2 \mathrm{mVs}^{-1} \mathrm{vs}$ SCE (b) cyclic voltammograms with scan rates 5 to $100 \mathrm{mVs}^{-1} \mathrm{vs} \mathrm{SCE}$.

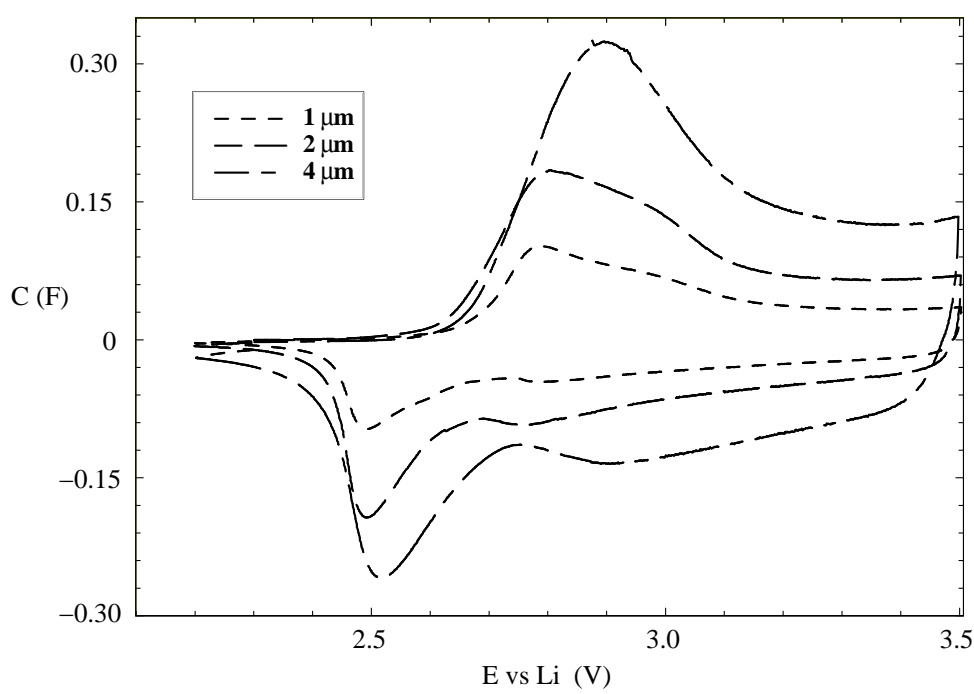

Fig. 2 Cyclic voltammograms of cells with capacity variations according to the PPy film thickness . Scan rate 0.2 $\mathrm{mVs}^{-1}$. 
This graph shows that the cycling capacity varies with the film thickness. Furthermore, it is seen that even at the same sweep rate, when the thickness is changed, peak position does not remain at the same potential. This is because for a thicker film, more energy is needed to obtain the maximum cycleable capacity and this is the reason for the shift in the peak position to higher potentials. This shift in the peak position could be due to the slower diffusion of ions in the thicker films as suggested by T. Osaka et al [5].

Table 1 illustrates the synthesis conditions and expected performance according to the thickness for PPy / DBS films..

Table 1 Synthesis and expected cycling charges for PPy / DBS films with different thicknesses.

\begin{tabular}{|c|c|c|}
\hline Thickness & Synthesis charge & Expected charge \\
\hline$(\mu \mathrm{m})$ & $(\mathrm{mC})$ & $(\mathrm{mC})$ \\
\hline 1 & 360 & 50 \\
\hline 2 & 720 & 100 \\
\hline 4 & 1440 & 200 \\
\hline
\end{tabular}

Synthesis charge was calculated considering that $360 \mathrm{mC} / \mathrm{cm}^{2}$ of charge density used during the electrochemical synthesis give rise to a film with $1 \mathrm{~mm}$ thickness [6]. Expected charge was estimated with the assumption of 0.33 anions per monomer incorporate during cycling. Table 2 shows the experimentally obtained charges for different film thicknesses for five different scan rates.

Table 2 Experimental cycling charges of PPy / DBS films with different thicknesses.

\begin{tabular}{|c|c|c|c|c|}
\hline & \multirow{2}{*}{$\begin{array}{l}\text { Scan rate } \\
\left(\mathrm{mV} \mathrm{s}^{-1}\right)\end{array}$} & \multicolumn{3}{|c|}{ Cycling charge according to thickness (mC) } \\
\hline & & $1 \mu \mathrm{m}$ & $2 \mu \mathrm{m}$ & $4 \mu \mathrm{m}$ \\
\hline \multirow[t]{5}{*}{ PPy : DBS } & 0.1 & 42 & 73 & 145 \\
\hline & 0.5 & 40 & 65 & 133 \\
\hline & 2.0 & 38 & 62 & 111 \\
\hline & 10.0 & 25 & 26 & 38 \\
\hline & 50.0 & 04 & 01 & 01 \\
\hline
\end{tabular}


One feature of the data in the table is that experimentally obtained charge is closer to the expected value for thinner electrodes at slow sweep rates. As an example, for $1 \mathrm{~mm}$ film $84 \%$ of the expected charge has been achieved while only $72 \%$ has been obtained for the $4 \mathrm{~mm}$ film. A possible reason to this is the slow diffusion of ions in the thicker films [7]. M. Alamgir et al have reported that a higher charge capacity can be expected from thinner electrodes since they have the high cathode utilization [8]. Difference exists between expected and experimentally obtained capacity values, especially with more thick electrodes at higher scan rates, may be due to low values of cycling charge. For the calculation of the expected charge, a doping level of 33\% was assumed. But the doping levels calculated with the synthesis and cycling charges end up with a value of 20-25\%.

Our results on one hand are better than the value of $24 \%$ reported for $\mathrm{Li} / \mathrm{PPy} / \mathrm{ClO}_{4}$ cell even with a liquid electrolyte [9]. This may be due to dual functionality of PAN electrolyte. On one hand, it is acting like a liquid phase and on the other hand, it has the mechanical properties of a solid electrolyte, which may have increased the cycling capacity. C. Arbizzani et al have reported a doping level of 15\% for a cell with PPy cathode film (made with $\mathrm{LiClO}_{4}$ ) and poly(ethyleneoxide) as the electrolyte [10]. Considering our results and what has been reported, it can be concluded that the performance of cells using PPy / DBS films as and PAN electrolyte can be maximised with a thinner PPy film. In addition, the results obtained verify that the PPy films made in aqueous medium have better qualities [11].

\section{ACKNOWLEDGEMENTS}

Our sincere thanks are due to Prof. Steen Skaarup and Prof. Keld West at Technical University of Denmark for their guidance. We wish to acknowledge International Programme for Physical Sciences (IPPS) Uppsala, Sweden for offering financial assistance.

\section{REFERENCES}

1. B. Scrosati , Conducting polymers:Advanced Materials for new design, rechargeable Lithium Batteries, Polymer International, 47, (1998) 50.

2. B. Scrosati, Electrode and electrolyte materials for polymer-based Lithium Batteries, J. Electrochem. Soc. 136, (1989) 2774.

3. K. M. Abraham, A. M. Alamgir, Li+ -Conductive solid polymer electrolytes with liquid like conductivity, J. of Electrochem. Soc., 137/5, (1990) 1657

4. T. A. Skothiem, S. W. Feldberg and M. B. Armend, Characteristics of electrochemically synthesized polymer electrodes, J. De. Physque, $\mathrm{C}_{3}-615$, (1983) 44.

5. Osaka, K. Naoi, S. Ogano, S. Nakamura, Dependence of film thickness on electrochemical kinetics of polypyrrole and properties of Li/polypyrrole battery performance, Journal of Electrochem. Soc., 134 / 9, (1987) 2096. 
6. A. F. Diaz, J. I. Castillo, Photochemical deposition of electrically conducting Polypyrrole, J. Chem Soc., Chem. Commun.,(1980) 397.

7. T. Osaka, K. Naoi, S. Ogano, Effect of polymerization anion on electrochemical properties of polypyrrole and on Li/LiClO4/PPy battery performance, Journal of Electrochem. Soc.,135/5, (1988) 1071.

8. M. Alamgir, R. D. Moulton, K. M. Abraham, Proceedings of the symposium on Primary and Secondary Lithium Batteries, Edited by K. M. Abraham, M. Salomon, The Electrochemical Society, (1989) 91.

9. S. Panero, P. Prosperi, F. Bonino and B. Scrosati, Chracteristics of electronically synthesizied polymer electrodes in Li cells-III polypyrrole, Electrchim. Acta., 32 / 7, (1987) 1007.

10. C. Arbizzani, M. Mastragostino, Performance of rechargeable cell with Polypyrrole film as cathode, Synthetic Metals, C663-C668, (1989) 28.

11. P. Novak, W. Vielstich, The influence of water on cycling behaviour of the PPy electrode in Li Cells, Journal of Electrochemical Society, 137 / 4, (1990) 1036. 